\title{
Students Suicides in Institutions of Higher Education in India: Risk Factors and Interventions
}

\author{
Vinita Pandey \\ Department of Sociology, Nizam College, Osmania University, India
}

\begin{abstract}
Suicides and attempts to suicide are no longer rare occurrences; we come across such incidents more often, the reasons may vary the end result remains the same. Though suicides have become common they are definitely not trivial and have considerable consequences. Suicides are not confined to a particular group or community though the analysis of causes suggests different reasons. Suicides among students of institutions of higher education in India is receiving considerable attention by the academicians, educators, government, community workers, social activists and various academic and legal bodies including University Grants Commission (UGC-the apex body of higher education in India), High Courts of different states in India and also Supreme Court of India. It is extremely important to understand why do students commit suicide? Several explanations can be found in theories of suicides including that of Emile Durkheim (1897), Patricia Hill Collins (1989), interactionist approach of Jack-Douglas (1967) and Ethnomethodological approach as suggested by Max Atkinson (1977) offer explanations to understand the crisis. Though suicides are not confined merely to student communities, it is definitely influenced by the complex socio-economic, cultural and psychological environment and milieu prevailing in institutions of higher education which propels the extreme step of ending one's life. The paper endeavors to understand the complex risk factors and interventions to minimize the risk. For the purpose of this paper students and youth is being used interchangeably though youth is a much broader demographic group.
\end{abstract}

Keywords Suicides, Higher Education, Caste, Ragging

\section{Introduction}

Suicide is not a sudden act or a state of mind which develops instantly. The person may have suicidal tendencies and can have thoughts which may persist over a period of time. The reasons for suicide can be mental disorders, personality disorder, bipolar disorder and schizophrenia, drug abuse or extreme alcoholism.

When a person feels all time low, dying seems to be the only option since they are not able to comprehend their own emotions and thoughts. Bell says" $\ldots$ lot of people criticize suicide victims, never having been in their position to fully comprehend the person's emotions or thoughts." (Bell, 2014)

According to Vikram Patel of London School of Hygiene \& Tropical Medicine suicide is one of the primary causes of death among young people in all countries and poorest countries of the world are no exception. He thus states that "It isn't surprising, then, that if you should speak to anyone affected by a mental illness, the chances are that you will hear stories of hidden suffering, shame and discrimination in nearly every sector of their lives." (Patel, 2012)

An Indian study by Gururaaj and Isaac showed that the suicide rate was highest in the 15-29 years age group (38 per 100,000 population) followed by the $30-44$ years group (34 per 100,000 population). The rate of suicide was 18 per 100,000 in those aged 45-59 years and 7 per 100,000 in those aged more than 60 years. (Gururaaj and Isaac, 2001) Since these figures are calculated for the general population and not the age-specific "population of interest", the higher risk in youth may reflect a higher representation of youth in the population.

Youth is a period whereby the risk of suicide increases. (Vijayakumar, John, Pirkis, Whiteford, 2005) In Indian youth suicide is one of the leading causes of death. (Aaron, Joseph, Abraham, Muliyil, George, Prasad , 2004)

The causes for students' suicide have been attributed to various psychological, biological and environmental factors. The suicide attempts have been also linked and associated with low educational achievement, examination / school performance stress. The newspaper Times of India (TOI) report on $22^{\text {nd }}$ March, 2013 highlighted the suicide of nine students who resorted to the extreme step when they tried in vain to cope with new challenges and academic pressure in the last 12 months in various varsities in Hyderabad.

The TOI report on suicides of students in educational

ISSN: 2332-6840 (Online) 2332-6832 (Print) Copyright (C) 2017 by authors, all rights reserved. Authors agree that this article remains permanently open access under the terms of the Creative Commons Attribution License 4.0 International License 
institutions was taken seriously and the then Acting Chief Justice N V Ramana of the AP High Court took suo motu cognizance (when a Government agency acts on its own cognizance) of the report. As a result of which notices were issued to the state and universities. The institutions had to appraise the court about the steps taken for suicide prevention. The TOI report was converted into public interest litigation. At that time, a group of 29 academicians, in a petition to the court, identified failure, fear of failure, administrative indifference, hostile regulations, insults, social and academic stigmatization and rejection as some of the reasons for suicide by students from marginalised groups. (Singh, 2016)

\section{Theorizing Suicides}

Suicides have been explained in multiple ways and have also been theorized. However the most prominent name which emerges is that of sociologist Emile Durkheim. He proposed a strong basis for a sociological perspective on the youth suicide. Durkheim owing to his work on suicides is indeed considered as one of the founding fathers of sociology and sociological thinking on suicide (Shea, 2013). In the words of Richard Sennett (2006, pp. xi-xxvii), who wrote an introductory piece to a recent translation of Durkheim's famous book, On Suicide:

"Durkheim saw that suicide has a social dimension. He observed that groups in which there is a good balance between individual initiative and communal solidarity have the lowest rates of suicide. Suicide cannot be understood simply as a form of mental illness. Less psychology and more sociology is required to make any sense of why some groups more than others might kill themselves."

According to Durkheim there are two key factors which impact rates of suicide: integration and regulation. For Durkheim, integration is the presence and importance of an individual's relationships and involvement in their communities; regulation is the presence and importance of norms, rules, and laws, both informal and formal. There has to be balance of these two factors. Excess or deprivation of either could result in suicide (Durkheim, 2006).

Jack Douglas (1967) enquires and questions the utilization of official statistics by Durkheim with regard to the 'facts' of suicide. Douglas argues that to understand suicides it's important to focus on what it means to individuals attempting it. It would be more relevant and meaningful to understand the perspective of those who had taken their lives. Thus it is more pertinent to examine suicide notes and family reactions. This will help us to reach at a more accurate figure of suicide. Thus, for Douglas the meaning of suicide to individuals is important.

There is a clear difference between Douglas work and that of Max Atkinson's (1977) study. Atkinson's main focus is on coroners' reports. Atkinson is keener to focus on how deaths are constructed as suicide in the coroners' proceedings. Atkinson does not focus so much upon individual meanings but on social processes.

Collins (1989) opines that there are multiple factors like race, class, and gender which interlock and generate various categories. They are also the foundation of "differences in our personal biographies". These social factors not only impact individually but also in conjunction with the other variables. It is thus very important to consider these variables. She asserts that we need to conceptualize race, class, and gender in order to understand them all as interconnecting and contributing factors to the construction of a person's selfhood. She writes particularly of their effects on oppression. She separates this oppression into three discrete categories: the institutional dimension of oppression, the symbolic dimension of oppression, and the individual dimension of oppression. Her "theory of intersectionality" is relevant to the study of youth suicide, because oppressive, external forces can either drive a person to self-destruction or draw them away from it.

\section{Discussion}

The literature suggests several risk factors responsible for students' suicides. Some of the factors are constant pressures of scoring well, meeting deadlines, increasing workload, ideas of excellence, competition, alienation, lack of space to share or even understand the stresses and despair generated from such pressures are leading the students to breaking down.

\section{The Risk Factors}

In the present paper the risk factors which have been identified and discussed in the following paragraphs are examination centric education system; depression; the caste factor; ragging and bullying in educational institutions; sexual orientation - issues of accepting LGBT; financial pressure and emotional neglect; forced career choices and not Speaking up.

\section{Examination Centric Education System}

The type of education system especially the examination centric education, pressure of studies and performance are critical factors in students' suicides. According to NCRB, in 2014 alone, 8,032 student suicides were reported.

Pressure to get good grades and pick a career at such a young age may not be handled by all. This pressure is increased by parents and families to live up to a certain standard. Since everyone is born with different talents aptitudes the pressure is too much to take.

Kota in Rajasthan (India) has become the nation's capital for test preparation. More than 160,000 students from across India came to Kota in 2015. But grueling study schedules, frequent tests and constant stress are taking a deadly toll. More than 70 students have committed suicide in the past five years in Kota, including 29 just last year. However as per NCRB data this rate is much higher than the national average of 10.6 suicides per 100,000 people. Educators at the 
private test academies admit that there is intense psychological pressure. "Students are under a constant state of anxiety here. They are unable to study, concentrate, remember, sleep or eat. They complain of headaches and breathlessness. Many just weep in front of me," said Madan Lal Agrawal, a psychiatrist in Kota who ran a help line for students for three years. Dr. Agrawal further explains that "They feel guilty because their parents have spent so much money and have high expectations. Parents often impose their own unfulfilled ambitions on their children." The test and competitive examination industry of $\$ 400$ is the result of fierce competition, poor quality of teaching standards, the unrealistic ambitions of parents and most significantly the rising middle-class aspirations( Laxmi, R, 2016).

According to Psychiatrist Dr. Sanjay Chugh the NCRB data clearly proves that in Indian education system things are only going from bad to worse. Chugh believes that our education system necessitates students to learn what they may never need in life. In many cases its quite irrelevant. "Why do we expose our children to such nonsense, with examinations becoming a do-or-die situation where students need a minimum percentage to get into a halfway decent college," asks Chugh. (Mukherji, 2011). The students are pushed to the extreme owing to an inadequate system, with lack of required social support. Parents have a critical role in destressing the youngsters. However to fulfill their own aspirations and their own desire to succeed the competition parents pressurize their children who are already burdened with the examination centric education system.

Professor Armaity Desai, former chairperson of the University Grants Commission, strongly opines that students' suicides are not being addresses by the Governments whether at state level or central level. The quality of education being imparted in the educational institutions is immensely compromised. This creates lot of pressure to perform especially in exams. This anxiety may lead to suicidal tendencies. There is serious academic competition. Students have a difficult time with the demands of classes, grades, choice of subjects and parental pressure to excel and opt for professional courses irrespective of the ward's abilities. Shyam Menon, Vice-Chancellor of Ambedkar University in Delhi says that there is a dramatic increase of students contesting for higher education in India. This has increased the competition to a great extent. Establishing linkages between employability and higher education, Menon believes that higher education has become a critical factor in social mobility. The high aspirations of Indian middle class have contributed in changes in the education system. These aspirations create stress to perform or perish. (Mukherji, 2011)

\section{Depression}

Depression is a very complex phenomenon and cannot be reduced to only a few causes. Its sources are multiple, layered, difficult to discern, but there are sources nonetheless located in our lives and its conditions. Depression affects various age groups including students and youngsters. The reasons may vary and if coping mechanism fails may lead to suicide.

\section{The Caste Factor}

The Caste system has been one of the critical factors exerting its presence in a wide spectrum of fields ranging from politics to marriage, from cultural practices to reservation system. The role of the caste system in education is debatable. On one hand we have those who feel they have been victimized in the educational set up owing to their backward caste status and on another hand we also have those who feel they have lost opportunities owing to presence of caste based reservations in education system.

Singh asserts that there is caste neutrality in our educational institutions. However, deeper examination and enquiry in to such issues reveals that casteism is an attitude problem, of department heads or authorities who represent these institutions. In only the last decade, ten suicide cases have come to light from Hyderabad University alone which is a clear reflection of caste presence in institutions of higher education. (Singh, 2016)

It is significant to understanding how various variables like race, gender, and class interact and intermingle and influence young people to harm themselves or prevent them from doing so. These variables also become factors of oppression. Collins (1989) discusses the symbolic and institutional dimension of oppression She contends that although our institutions project the ideology of equal opportunity for all, the fact is that racism, sexism, and classism exist everywhere be it in schools, businesses, hospitals, government agencies, and so on. These forms of prejudices and discrimination exist in disguise (Collins, 1989, p. 6-7). This analogue can be extended in Indian context to understand caste as a factor of students harming themselves.

It has been questioned whether the discrimination in higher education in India a real problem? Are these highlighted suicides as intrinsically connected to India's power structure as shown by the media?

The 'Report of the Committee to Enquire into the Allegation of Differential Treatment of SC/ST Students in AIIMS, Delhi (2006)' contains findings by a three-member committee constituted by the Government, to probe into the matter of discrimination and differential treatment in the All India Institute of Medical Sciences (AIIMS) Delhi, one of the top medical colleges in the country. Students in the college belonging to $\mathrm{SC} / \mathrm{ST}$ face severe discrimination by their peers, from ragging to segregation and isolation. They also face differential treatment from their teachers in the form of avoidance, negligence, discouragement, and discrimination in evaluation. This affects their performance and overall growth.

The report noted aggression against students from lower castes in every aspect of their daily lives - from the classroom to faculty interaction, from the hostel and mess to examinations - making their ostracization from the 
community activities of the institute a bitter reality. The committee made many specific and pointed recommendations for the improvement of the administration of educational institutions, but even after a decade there has been no action on any of those pointed suggestions. (Chukka, 2016)

A committee to study the problems of marginalised community students in 2014 pointed out that students from marginalised backgrounds experience a strong sense of alienation and disaffection within the university set-up, which needs to be addressed immediately. (Nautiyal, 2016)

\section{Ragging and Bullying in Educational Institutions}

Ragging in India is a damaging and detrimental interaction of the seniors in college or school with the juniors, new entrants or first years. It often involves insults (simple or suggestive sexual, sarcastic and even physical), running errands for seniors, and many other complex activities. It has leading to several complaints of serious injury to the victims. There are stringent laws pertaining to ragging in India. Ragging is an act that violates or is perceived to violate an individual student's dignity.

Bullying is a "no holds barred" scenario wherein everyone is the target of the bully whether he/she is a batch mate or junior or senior. Ragging is not Bullying. The differences are subtle but well defined. Bullying and ragging may range from pranks to name calling.

Bell asserts those students who are bullied feel cornered and their self-esteem and confidence is beaten down to the bare minimum. There is feeling of worthlessness to such an extent that there seems to be no meaning in life or living. This leads to depression and in extreme cases students end up taking their own lives. Unfortunately since students are scared of further bullying they fear bringing up what's happening to their teachers or parents and these things tend to go unnoticed for years on end. (Bell, 2014)

Cyber-Bullying has witnessed youngsters being mocked and made fun of. This leads to having low self-esteem eventually leading to several other problems associated with it including depression and other mental disorders. This may also lead to eventually take their own lives.

\section{Sexual Orientation - Issues of Accepting Lesbians, Gay, Bisexual, Transgender, Queer (LGBTQ)}

It is mostly in their young years that one gains clarity with regard to their sexuality. If they realize that they are gay, lesbian, bisexual, or whatever other sexuality they fit themselves in comes with its own set of difficulties. It is very difficult to accept and also to convey to family, friends and peers owing to stigma associated with it. Mostly parents and family do not understand the sexual orientation creating immense pressure on the youngster.

This "coming out" that already took so much courage is now being pummelled. There is an inner conflict in being themselves and what society's view of them. This eventually leads to a depression. The teen actually starts to believe that he is as a bad a person that people make him out to be. Thus there is feeling that living is no longer worth it. Especially if living means not being able to love who he chooses to love. (Bell, 2014)

Collins asserts that the symbolic dimension of oppression is comprised of "widespread, societally sanctioned ideologies used to justify relations of domination and subordination". These relations of domination and subordination influence the social construction and perception of race, gender, class status, and sexual orientation. The considerations of masculinity and feminity in the society are the reflections of dominant group. The symbolic dimension of oppression results in the rigid social construction of gender, determining that a man is expected to be "aggressive, rational, strong," and a woman should be "passive, emotional, and weak". The minorities and the disadvantaged whether in age, sexual orientation, race, gender, or class - are left unrepresented and abandoned. (Collins, 1989, p. 10-11).

Gwalani (2015) highlights the following factors for high suicide rates among LGBTQ youth apart from high prevalence of bullying and ridicule aimed at them by classmates in school and college

- Pressure from family and society to enter 'normal' relationships, get married

- Lack of emotional support when things go wrong in relationships

- Feeling that the relationship cannot reach its natural conclusion

- Physical and emotional violence within the relationship

- Fear of partner bowing to family pressure and getting married

- Being scared about not finding love again, given the less number of LGBT people in society

- Pressure of always keeping the relationship under wraps

Psychiatrist Dr Shreyas Magia explains that their relationships being seen as 'abnormal' by the society at large means a LGBTQ person could not share the details with family or friends, a factor that increased their distress and makes them emotionally more vulnerable and fragile. "A big cause for concern for these youngsters is that the relationship can hardly reach a point of conclusion. This causes further turmoil and affects the person's self-esteem as well. All these factors interfere with their ability to keep up with other pressures and take up the responsibilities that a relationship brings along," he said. He reasons that panic attacks, nervous breakdowns and depression are also pretty common among LGBT youth. (Gwalani, 2015)

\section{Financial Pressure and Emotional Neglect}

The students may face financial pressure to support their education, identity problems, social isolation along with emotional neglect.

The signs of suicides are ignored by parents owing to their hectic lifestyles. The emotional neglect and feeling of emotional deprivation clubbed with teen feeling forgotten 
about and alone intensifies the emotional pressure. This emotional neglect makes them feel that even if they end their lives it would make absolutely no difference and their absence will not even be noticed. "This emotional neglect has a worse effect than some people can imagine." (Bell, 2014)

\section{Forced Career Choices and Not Speaking Up}

In our country, generally many students succumb to very high amount of pressure, especially from their family and teachers in terms of their career choices and studies.

In most of the student suicide cases, the causes are unknown. However there are critical questions including could this be because the victim was not comfortable expressing their concerns even for one last time? Why did they choose to suffer in silence? In many cases, it so happens that the victims find it hard to freely express their concerns about the pressure they are dealing with, even with their parents.

\section{Interventions to Minimize Risk Factors}

Suicide is being identified as a critical issue of public health. There are constant efforts and interventions by the government agencies including public health department, Non-Government Organisations and policy making bodies of educational institutions to strengthen the resilience among students.

Vikram Patel is of the opinion that the there is strong evidence which suggests that timely care along with interventions in terms of medicines, socio-psychological interventions can make a vast difference. But majority of these affected individuals do not receive the care that can make a difference. (Patel, 2016)

Ragging has been identified as one of the risk factors for suicide. The Ministry of Human Resources Development (MHRD), Government of India subsequent to a directive by the Supreme Court, appointed a seven member panel headed by ex-CBI director Dr. R. K. Raghavan to recommend anti-ragging measures. The Dr. R.K.Raghavan Committee submitted its report to the Hon'ble Supreme Court in May 2007. As per the recommendations, the Hon'ble Supreme Court of India makes it mandatory for academic institutions to file official F.I.R (First Information Report) with the police in any instance of a complaint of ragging. This is done to ensure that all cases instead of investigated by academic institutions are formally investigated under criminal justice system.

In 2009, in the wake of Aman Kachroo's death (first year medical student), University Grants Commission (UGC) passed UGC Regulation on curbing the Menace of Ragging in Higher Educational Institutions, 2009. These regulations give clear directives to College administration and authorities to curb the menace of ragging. The directives also necessitate stringent measures and proactive steps like accommodating freshers in a separate hostel, conducting surprise raids especially at nights by the anti-ragging squad and submission of affidavits by all senior students and their parents taking oath not to indulge in ragging.

The University Grants Commission in January, 2016 has asked all universities to set up a "students counselling system" to deal with all sorts of problems that the students might face. Directives have been given regarding the student counselling system. The system should address all common concerns of students, such as anxiety, stress, fear of failure, to homesickness and other academic troubles. The system should involve students, teachers and parents, and should be target oriented and interactive.

There exists a widespread research on various risk and protective factors in which influence youth suicides; however there has not been adequate research to develop structured prevention programs or to demonstrate which programs actually work. Kisch etal. (2005) commented, "If treatment does, in fact, reduce risk, the proof will need to be found in treatment outcome studies over a greater period of time" (p. 10). There are several institutions which offer free counseling services. But the students who are most in need do not utilize the services. The reluctance to seek help is rooted in the socio-cultural stigmatization of suicidal behaviors.

\section{Conclusions}

Students' suicides in institutions of higher education have emerged as a serious social problem in India. There is matrix of issues and factors which are responsible for the stuents suicides. What makes an individual take such an extreme decision to end life? What is it that makes life not worth living in the age which is perceived as the most happening and promising period of life. Is the youth becoming less tolerant or is it that failures are not taken in to stride with grace? There are multiple such questions pertaining to students' suicide. There are complex socio-economic factors, psycho-cultural factors which lead to suicides. The risk factors which have been discussed in this paper are examination centric education system; depression; the caste factor; ragging and bullying in educational institutions; sexual orientation - issues of accepting LGBT; financial pressure and emotional neglect; forced career choices and not speaking up. The paper also discusses the interventions to minimize risk factors

Several interventions have been initiated to minimize the risk in institutions of higher education in India. The above discussion however clearly mirrors the fact that the risk factors leading to students' suicide are not confined to educational institutions alone. There are several external influences which are beyond the jurisdiction of educational institutions. Thus the intervention programmes for suicide prevention has to both at macro and micro level. Moreover there is also need to take up specific research on effectiveness of various interventions. This will also facilitate in strengthening the effective interventions. 
It is extremely important to understand that suicide is not a solution. It not only devastates their own but many other lives. There is help available out there! There are counsellors, psychologists and even special friends who are more than willing to help them cope with it.

\section{Acknowledgements}

My deepest gratitude to the anonymous reviewers, Ms Elizabeth Carter, Research Assistant to Dr. Venkat Pulla. This paper wouldn't have been possible without the support, encouragement and patience of Dr. Venkat Pulla and Mr. Mamidi Bharat Bhushan. Thank you Dr. Venkat Pulla for such a wonderful journey of learning.

\section{REFERENCES}

Aaron R, Joseph A, Abraham S, Muliyil J, George K, Prasad J, et al. Suicides in young people in rural southern India. Lancet. 2004;363:1117-8. [PubMed]

Atkinson, J. M., (1977), 'Societal reactions to suicide: the role of the coroners' definitions', in Cohen, S. (Ed.) Images of Deviance. Harmondsworth, Penguin

Bell, Chelsea (July 3 2014).

http://listcrux.co/top-10-reasons-teenagers-commit-suicide/

Douglas, J.D., (1967), The Social Meanings of Suicide. Princeton, Princeton University Press

Chukka, Vikram. (18/01/2016). Scholar's Suicide: Discrimination in Higher Education Reflects the Violence of a Casteist Culture. Retrieved fromhttp://thewire.in/19548/scholars-suicide-discrimina tion-in-higher-education-reflects-the-violence-of-a-casteist-culture /

Collins, P.H. (1989, May 24). Toward a new vision, Race, class and gender as categories of analysis and connection in Shea. P. Emily (2013) The Sociology of Youth Suicide: Risk and Protective Factors library.emmanuel.edu/archive/sites/default/files/Shea_E_Thesiso.p df
Durkheim, E. 2006 (1897). On suicide. London, England: Penguin Classics.

Gururaj G, Isaac MK. Epidemiology of suicides in Bangalore. Bangalore: National Institute of Mental Health and Neuro Sciences; 2001. Report No.: Publication No 43.

Gwalani, Payal (Nov 17, 2015). High rate of suicides haunts LGBT youths. Retrieved from http://timesofindia.indiatimes.com/city/nagpur/High-rate-of-suicid es-haunts-LGBT-youths/articleshow/49808926.cms

Kisch, J., Leino, E.V., \& Silverman, M.M. (2005). Aspects of suicidal behavior, depression and treatment in college students: Results From the Spring 2000 National College Health Assessment Survey. Suicide and Life Threatening Behavior, 35, 3-13.

Laxmi, R. (2016, January 25). A spate of suicides highlight the pressures on students in India. The Washington Post. Retrieved from

https://www.washingtonpost.com/world/asia pacific/a-spate-of-su icides-highlights-the-pressures-on-students-in-india/2016/01/23/8c a5d7de-acbf-11e5-b281-43c0b56f61fa story.html?utm term=.60d $79371747 \mathrm{~d}$

Mukherji, Anahita (2011). Retrieved from

http://timesofindia.indiatimes.com/india/Student-suicides-soar-26in-5-years-education-system-blamed/articleshow/10573202.cms

Nautiyal, Shashi. (2016). Casteism in Education System. International Journal of education and applied research. Vol. 6, Issue 1, spl-1, Jan-June 2016

Patel, Vikram (2012). Retrieved from https://www.ted.com/talks/v ikram_patel_mental_health_for_all_by_involving_all/transcript?la nguage $=\mathrm{en} \# \mathrm{t}-22560 \overline{1}$

Sennett, R. (2006 [1897]). [Introduction]. In E. Durkheim (Author), On suicide (pp. xi-xxvii). London, England: Penguin Classic.

Shea. P. Emily (2013) The Sociology of Youth Suicide: Risk and Protective Factors

library.emmanuel.edu/archive/sites/default/files/Shea E Thesiso.p df

Singh, Shrini (March 15, 2016). The Bitter Truth of Suicides in Higher Education in India. Retrieved from

http://www.thecitizen.in/index.php/NewsDetail/index/8/7139/TheBitter-Truth-of-Suicides-in-Higher-Education-in-India

Vijayakumar L, John S, Pirkis J, Whiteford H. (2005). Suicide in developing countries Retrieved from https://www.ncbi.nlm.nih.gov/pubmed/16276753 